\title{
ANALISIS KONSENTRASI KARBON MONOKSIDA (CO) PADA RUANG PARKIR AYANI MEGA MALL KOTA PONTIANAK
}

Syarifah Apriyanti N. $\mathrm{H}^{1)}$ Yulisa Fitrianingsih(1) Suci Pramadita ${ }^{1)}$

1) Program Studi Teknik Lingkungan Jurusan Teknik Sipil Fakultas Teknik Universitas Tanjungpura, Pontianak Email: syf.apriyanti.nh@gmail.com

\begin{abstract}
ABSTRAK
Karbon monoksida (CO) merupakan salah satu gas hasil pembakaran tidak sempurna kendaraan bermotor yang dapat mencemari udara dan mengganggu kesehatan manusia. Potensi gas karbon monoksida yang menjadi pencemar di dalam ruangan akibat minimnya sirkulasi udara, maka dilakukan suatu studi untuk mengetahui nilai konsentrasi gas $\mathrm{CO}$ pada ruang parkir berdasarkan perbedaan interval waktu, juga untuk mengetahui hubungan korelatif jumlah kendaraan terhadap konsentrasi $\mathrm{CO}$, dan untuk mengetahui hubungan komparatif konsentrasi $\mathrm{CO}$ di tempat terbuka dan tempat tertutup. Penelitian dilakukan di Ayani Mega Mall Kota Pontianak dengan 4 titik ukur yaitu Titik 1 dan Titik 2 di lantai dasar, serta Titik 3 dan Titik 4 di lantai atap. Pada tiap titik diukur nilai CO menggunakan CO Meter selama 1 jam untuk interval waktu pagi, siang, sore, dan malam. Dihitung pula jumlah kendaraan pada waktu tersebut. Berdasarkan hasil penelitian, nilai konsentrasi CO pada parkir dalam gedung Ayani Mega Mall Pontianak mengalami nilai tertinggi di Titik 1 pada kondisi siang hari untuk hari libur, yaitu dengan angka 12,92 ppm, sedangkan untuk hari kerja nilai tertinggi di Titik 1 pada kondisi malam hari, yaitu dengan angka 9,58 ppm. Nilai tersebut masih di bawah nilai ambang batas ( $25 \mathrm{ppm}$ ) berdasarkan Peraturan Menteri Tenaga Kerja dan Transmigrasi nomor 13 tahun 2011. Selanjutnya hubungan antara jumlah kendaraan terhadap konsentrasi CO memiliki angka koefisien korelasi sebesar 0,703 untuk hari libur dan 0,798 untuk hari kerja, yang berarti memiliki hubungan yang berkorelasi kuat yaitu semakin banyak kendaraan maka nilai CO juga meningkat. Hubungan komparasi menggunakan uji Kruskall Wallis menghasilkan angka asymp sig sebesar 0,044 untuk hari libur dan sebesar 0,01 untuk hari kerja, yang mana kurang dari taraf signifikansi sebesar 0,05 dengan simpulan ada beda nilai karbon monoksida di tiap titik, di mana nilai konsentrasi karbon monoksida di tempat tertutup lebih besar daripada di tempat terbuka. Hal ini terjadi karena keterbatasan ruang di tempat tertutup sehingga gerakan udara terbatas, sedangkan di tempat terbuka karbon monoksida dapat langsung menyebar sehingga konsentrasi karbon monoksida lebih cenderung kecil.
\end{abstract}

Kata kunci : kualitas udara, pencemaran udara dalam ruang, karbon monoksida (CO), ruang parkir, Ayani Megamall Pontianak

Carbon monoxide $(\mathrm{CO})$ is a result of incomplete combustion gas of motor vehicles that pollute the air and damage the humans' health. The potential of carbon monoxide gas presence becoming a pollutant in the room due to lack of air circulation, thus, a study is conducted to determine the concentration of $\mathrm{CO}$ in parking spaces with different time intervals, as well as to determine the correlative relationship between number of vehicles and the concentration of $\mathrm{CO}$, and to determine the comparative relationship of concentration of $\mathrm{CO}$ in open and enclosed spaces. The study was conducted in Ayani Mega Mall Pontianak City with 4 measuring point, namely Point 1 and Point 2 on the ground floor, as well as Point 3 and Point 4 on the rooftop. At each point, the value of $C O$ were measured by using CO Meter for 1 hour on each interval of time in the morning, afternoon, evening, and night. The number of vehicles at that period were also counted. Based on the study results, the value of $\mathrm{CO}$ concentration in parking on Ayani Mega Mall Pontianak experienced the highest value at point 1 during daylight conditions on weekend, with the numbers $12.92 \mathrm{ppm}$, while on weekday the highest value is at point 1 on a night conditions, with the number of $9.58 \mathrm{ppm}$. These value is still below the threshold value (25 ppm) based on the Minister of Manpower and Transmigration Decree Number 13 in 2011. Furthermore, the correlation between the number of vehicles and the concentration of $\mathrm{CO}$ has a number correlation coefficient of 0.703 for weekend and 0.798 for weekday, which means it has strong correlations where the more vehicles, the bigger the concentration of $\mathrm{CO}$. The comparative relationship by using Kruskal test shows the asymp sig number of 0,044 for holiday and 0,01 for working days, which is less than the significance level of 
0.05 with the notion that there were different concentration of carbon monoxide at each point, in which the value of concentration carbon monoxide in enclosed place is greater than in the open space. This occurs due to the limitation of space in an enclosed space so air movement is also limited, while in the open space carbon monoxide can be directly spread thus the concentrations of carbon monoxide is more likely to be small

Keyword : air quality, indoor air pollution, carbon monoxide (CO), parking spaces, Ayani Megamall Pontianak

\section{PENDAHULUAN}

Dominasi sumber pencemar udara di kota besar adalah dari kendaraan bermotor. Demikian pula dengan pencemaran udara dalam ruang, di mana terdapat sumber pencemar udara dari transportasi di gedung, misalnya gedung parkir. Letak ruangan yang tertutup tersebut berpotensi memiliki durasi yang lebih lama dalam menerima beban pencemaran dari emisi kendaraan bermotor karena emisi tersebut sulit keluar dan sulit terurai di dalam ruang parkir. Kendaraan bermotor mengeluarkan gas buangan atau emisi, salah satunya yaitu karbon monoksida (CO) yang merupakan hasil pembakaran tidak sempurna kendaraan yang apabila dalam kondisi berlebih dapat mengisolasi bumi sehingga bumi menjadi panas dan dapat menyebabkan gangguan kesehatan apabila melebihi nilai ambang batas sebesar 25 ppm (PER.13/MEN/X/2011). Adanya potensi kadar CO yang tinggi dalam ruangan parkir yang dapat membahayakan manusia, maka dilakukan suatu studi untuk mengetahui besarnya konsentrasi CO tersebut. Salah satu lokasi di Kota Pontianak yang rentan akan potensi tersebut adalah Ayani Mega Mall Pontianak.

Adapun tujuan dari penelitian ini antara lain mengetahui nilai konsentrasi gas CO pada parkir dalam gedung Ayani Mega Mall Pontianak berdasarkan perbedaan interval waktu, mengetahui hubungan korelatif jumlah kendaraan terhadap konsentrasi $\mathrm{CO}$, mengetahui hubungan komparatif konsentrasi CO di tempat terbuka dan tempat tertutup. Dengan diketahuinya kualitas udara dalam ruangan berupa data karbon monoksida (CO) diharapkan dapat menjadi rekomendasi bagi pihak terkait untuk melakukan pencegahan dan pengendalian, memberikan informasi mengenai kondisi ruangan kepada masyarakat akan pentingnya sirkulasi udara dalam ruangan untuk mencegah terjadinya pencemaran udara dalam ruang, serta menjadi rekomendasi pengembang bangunan lainnya untuk memperhatikan kualitas udara dalam ruangan dalam pembangunan di masa mendatang.

\section{METODOLOGI PENELITIAN}

Penelitian dilakukan di ruang parkir lantai dasar dan ruang parkir teratas Ayani Mega Mall Kota Pontianak. Pengukuran pada lantai dasar dilakukan di dekat pintu masuk parkir yang biasanya terjadi antrean (Titik 1), dan titik tempat menunggu untuk menaikturunkan pengunjung yang terletak di dekat pintu masuk ke mall (Titik 2). Sedangkan untuk lantai teratas diambil titik di dekat ramp yang merupakan arus naik-turun (Titik 3 ) dan di titik pintu masuk bioskop (Titik 4). Pengambilan sampel dilakukan pada hari Senin yang mewakili hari kerja dan hari Sabtu yang mewakili hari libur, untuk melihat variasi konsentrasi ketika hari kerja dan hari libur. Berdasarkan Permen LH No 12 tahun 2010 tentang Pelaksanaan Pengendalian Pencemaran Udara di Daerah, pemantauan dilakukan dengan interval waktu pagi, siang, sore dan malam. Masing-masing interval waktu diukur 1 (satu) jam.

Data primer yang dibutuhkan adalah nilai CO dan jumlah kendaraan. Data sekunder yang digunakan adalah layout ruang parkir yang didapatkan dari pihak manajemen Ayani Mega Mall. Adapun alat yang dibutuhkan untuk pengambilan data primer yaitu $\mathrm{CO}$ meter 
merek Lutron GCO-2008. Alat diletakkan $\pm 1,5$ meter dari permukaan tanah sesuai dengan rata-rata tinggi untuk bernafas dengan pencatatan tiap 5 menit. Selain itu digunakan juga perhitungan jumlah kendaraan secara manual menggunakan kertas dan pulpen.

Setelah mendapatkan data yang diperlukan, selanjutnya dilakukan analisis, yaitu dengan software Microsoft Excel untuk menghimpun data, dengan software SPSS untuk mengetahui hubungan antara konsentrasi CO dengan jumlah kendaraan (uji korelasi) menggunakan Uji Korelasi Spearman, dengan software SPSS untuk mengetahui ada tidaknya hubungan antara konsentrasi CO dengan perbedaan titik (uji komparasi) menggunakan Uji Kruskall Wallis.

3. HASIL DAN PEMBAHASAN

A. DATA KONSENTRASI GAS KARBON MONOKSIDA

Tabel 1. Hasil Pengukuran pada Hari Libur

\begin{tabular}{|c|c|c|c|c|c|}
\hline Waktu & Titik & CO (ppm) & $\mathrm{CO}(\mu \mathrm{g} / \mathrm{Nm} 3)$ & Suhu $\left({ }^{\circ} \mathrm{C}\right)$ & Jumlah Kendaraan (unit) \\
\hline \multirow{4}{*}{ Pagi } & 1 & 0,92 & $1.145,83$ & 30,77 & 17 \\
\hline & 2 & 4,33 & $5.416,67$ & 31,07 & 9 \\
\hline & 3 & 0,50 & 625,00 & 31,90 & 14 \\
\hline & 4 & 0,08 & 104,17 & 32,89 & 4 \\
\hline \multirow{4}{*}{ Siang } & 1 & 12,92 & $16.145,83$ & 34,21 & 329 \\
\hline & 2 & 5,42 & $6.770,83$ & 31,56 & 64 \\
\hline & 3 & 3,25 & $4.062,50$ & 34,76 & 90 \\
\hline & 4 & 0,42 & 520,83 & 38,38 & 55 \\
\hline \multirow{4}{*}{ Sore } & 1 & 5,92 & $7.395,83$ & 33,96 & 397 \\
\hline & 2 & 2,17 & $2.708,33$ & 33,34 & 60 \\
\hline & 3 & 3,67 & $4.583,33$ & 31,35 & 123 \\
\hline & 4 & 0,58 & 729,17 & 30,91 & 62 \\
\hline \multirow{4}{*}{ Malam } & 1 & 11,25 & $14.062,50$ & 33,28 & 419 \\
\hline & 2 & 1,83 & $2.291,67$ & 33,34 & 43 \\
\hline & 3 & 3,83 & $4.791,67$ & 31,19 & 192 \\
\hline & 4 & 1,17 & $1.458,33$ & 29,46 & 143 \\
\hline
\end{tabular}

Berdasarkan Tabel 1, terlihat nilai tertinggi berada di Titik 1 pada waktu siang hari dengan angka $12,92 \mathrm{ppm}$ dengan kondisi suhu $34,21^{\circ} \mathrm{C}$ dan jumlah kendaraan yang melintas sebanyak 329 unit. Sedangkan nilai terendah di Titik 4 pada waktu pagi dengan angka $0,08 \mathrm{ppm}$ dengan kondisi suhu $32,89^{\circ} \mathrm{C}$ dan jumlah kendaraan yang melintas sebanyak 4 unit.

Berikutnya untuk hari kerja, diperoleh data seperti pada Tabel 2. Terlihat nilai tertinggi berada di Titik 1 pada waktu malam hari dengan angka 9,58 ppm dengan kondisi suhu $32,78^{\circ} \mathrm{C}$ dan jumlah kendaraan yang melintas sebanyak 376 unit. Sedangkan nilai terendah di Titik 4 pada waktu pagi dengan angka $0,00 \mathrm{ppm}$ dengan kondisi suhu $35,37^{\circ} \mathrm{C}$ dan jumlah kendaraan yang melintas sebanyak 3 unit. 
Tabel 2. Hasil Pengukuran pada Hari Kerja

\begin{tabular}{|c|c|c|c|c|c|}
\hline Waktu & Titik & CO (ppm) & $\mathrm{CO}(\mu \mathrm{g} / \mathrm{Nm} 3)$ & Suhu $\left({ }^{\circ} \mathrm{C}\right)$ & Jumlah Kendaraan (unit) \\
\hline \multirow{4}{*}{ Pagi } & 1 & 2,83 & $3.541,67$ & 31,09 & 51 \\
\hline & 2 & 1,75 & $2.187,50$ & 31,03 & 26 \\
\hline & 3 & 0,92 & $1.145,83$ & 32,74 & 8 \\
\hline & 4 & 0,00 & 0,00 & 35,37 & 3 \\
\hline \multirow{4}{*}{ Siang } & 1 & 5,17 & $6.458,33$ & 34,11 & 215 \\
\hline & 2 & 1,83 & $2.291,67$ & 32,76 & 82 \\
\hline & 3 & 1,5 & $1.875,00$ & 34,68 & 30 \\
\hline & 4 & 0,08 & 104,17 & 39,91 & 14 \\
\hline \multirow{4}{*}{ Sore } & 1 & 4,42 & $5.520,83$ & 33,43 & 210 \\
\hline & 2 & 2,67 & $3.333,33$ & 32,92 & 42 \\
\hline & 3 & 1,58 & $1.979,17$ & 31,57 & 33 \\
\hline & 4 & 0,25 & 312,50 & 30,94 & 18 \\
\hline \multirow{4}{*}{ Malam } & 1 & 9,58 & $11.979,17$ & 32,78 & 376 \\
\hline & 2 & 6,67 & $8.333,33$ & 32,21 & 49 \\
\hline & 3 & 4,42 & $5.520,83$ & 30,71 & 47 \\
\hline & 4 & 0,67 & 833,33 & 28,65 & 51 \\
\hline
\end{tabular}

Nilai ambang batas untuk karbon monoksida berdasarkan Peraturan Menteri Tenaga Kerja dan Transmigrasi tentang Nilai Ambang Batas Faktor Fisika dan Faktor Kimia di Tempat Kerja (PER.13/MEN/X/2011) adalah 25 ppm. Nilai ini merupakan batasan maksimum karbon monoksida yang diperkenankan dalam suatu lingkungan kerja. Berdasarkan hasil pengukuran tidak ada nilai terukur yang melewati nilai ambang batas.

Bila melihat angka CO dan suhu saja, terlihat kecendrungan nilai karbon monoksida berbanding lurus dengan suhu di mana bila CO tinggi maka suhu juga tinggi. Bila melihat dari jenis ruangan, ruang tertutup (Titik 1 dan Titik 2) nilai $\mathrm{CO}$ selalu berbanding lurus dengan suhu baik kondisi pagi, siang, sore, maupun malam. Namun pada ruang terbuka (Titik 3 dan Titik 4) kondisi berbanding lurus antara $\mathrm{CO}$ dan suhu hanya terjadi pada kondisi sore dan malam sedangkan pada kondisi pagi dan siang berbanding terbalik.

Perbedaan jenis ruangan tersebut ternyata turut memengaruhi suhu. Menurut hasil penelitian Tsuchiya (2006), Ariliyanti (2012), dan Rorah (2014) yang meneliti hubungan CO dengan suhu di ruangan tertutup menyatakan suhu tidak mempengaruhi konsentrasi karbon monoksida secara signifikan karena perbedaan suhu yang tidak jauh atau suhu cenderung stabil. Namun di penelitian ini terjadi kecenderungan suhu berbanding lurus dengan nilai karbon monoksida di ruang tertutup meskipun perbedaan suhu tidak terlalu jauh. Hal ini disebabkan oleh kurangnya pertukaran udara di dalam ruangan sehingga udara panas hasil dari pembakaran bahan bakar kendaraan tidak dapat berpindah dengan cepat dalam ruangan tertutup.

Sedangkan pada kondisi pagi dan siang di ruang terbuka yang memiliki hubungan tidak linier antara nilai CO dengan suhu disebabkan oleh terjadinya keadaan atmosfer yang tidak stabil (kondisi superadiabatik) di mana sifat udara bergerak secara vertikal sehingga terjadi turbulensi. Adanya turbulensi akan memancing dispersi sehingga pencemar dapat akan naik, terekspansi, menjadi lebih encer atau ringan dan lebih dingin. Sedangkan pada kondisi sore dan malam hari armosfer bersifat stabil (kondisi subadiabatik) di mana sifat udara bergerak secara horizontal yang menahan polutan tidak 
bergerak naik sehingga polutan tidak terdispersi (Peavy (1986) dalam Yarianto (1999)). Selain karena sifat suhu tersebut, menurut Yaziz \& Yen (1986) pengurangan arus kendaraan diperkirakan akan mengurangi nilai karbon monoksida, namun pengurangan suhu diperkirakan tidak akan mengurangi nilai karbon monoksida.

Berkaitan dengan waku pengambilan, pada kondisi pagi hari nilai CO dominan tinggi di Titik 2 untuk hari libur dan di Titik 1 di hari kerja. Sedangkan untuk kondisi siang, sore, dan malam hari nilai CO dominan tinggi di Titik 1 baik hari kerja maupun hari libur. Perbedaan waktu dan hari tidak memengaruhi nilai $\mathrm{CO}$ di ruang tertutup secara langsung, namun memengaruhi volume dan aktivitas kendaraan yang berada di titik pengukuran. Baik pada hari kerja maupun hari libur, nilai karbon monoksida tertinggi berada di Titik 1 , yaitu 12,92 ppm untuk hari libur dan 9,58 ppm untuk hari kerja. Titik 1 bernilai lebih tinggi dari titik lainnya disebabkan oleh jumlah kendaraan yang ada lebih banyak dari titik lain, sering terjadi kondisi idle (mesin menyala namun tidak bergerak) dari mengantre sehingga emisi yang dikeluarkan tidak terurai dan menumpuk, serta mengalami pembakaran bahan bakar yang lebih banyak ketika kendaraan naik rampa.

Rampa (ramp) adalah bidang miring, yang dalam hal ini berfungsi sebagai jalan naik dan turun untuk kendaraan. Keberadaan rampa yang memiliki ketinggian dan kemiringan tertentu membuat kendaraan mengalami perlambatan ketika berbelok, percepatan ketika naik, dan perlambatan ketika berbelok di lantai berikutnya. Menurut Rao \& Rao (1989) konsentrasi CO akan meningkat terutama saat mesin kendaraan idle (4-6\%), ketika mulai memacu (0-6\%), dan ketika mengalami perlambatan (2-4\%), namun relatif rendah saat berjalan normal (1-4\%).

\section{B. KORELASI NILAI KARBON MONOKSIDA DENGAN JUMLAH KENDARAAN}

Pada pengamatan yang dilakukan, terdapat kecenderungan nilai $\mathrm{CO}$ akan meningkat seiring dengan pertambahan jumlah kendaraan. Hal ini selanjutnya akan dibuktikan dengan hipotesa statistik dengan menggunakan uji korelasi Spearman menggunakan aplikasi SPSS (Statistic Product and Service Solutions). Sebelumnya, data hasil pengamatan diuji dengan uji normalitas Shapiro-Wilk untuk menentukan uji lanjutan. Uji Shapiro-Wilk baik digunakan untuk data berjumlah 7-50, sedangkan jumlah data yang dianalisis 16. Analisis normalitas Shapiro-Wilk memiliki kriteria, yaitu apabila nilai signifikansi (sig) $<0,05$ berarti distribusi tidak normal, sedangkan bila nilai signifikansi (sig) $\geq 0,05$ berarti distribusi normal. Dari hasil signifikansi didapatkan data bersifat tidak normal. Maka dari itu untuk hubungan korelatif menggunakan metode Uji Spearman Rank sedangkan untuk hubungan komparatif menggunakan metode Uji Kruskall Wallis.

Selanjutnya dilakukan uji korelasi Spearman untuk melihat korelasi antara nilai karbon monoksida dengan jumlah kendaraan. Uji korelasi Spearman memiliki ketentuan, yaitu apabila nilai signifikansi (sig) $<0,05$ berarti ada hubungan korelasi, sedangkan bila nilai signifikansi (sig) $\geq 0,05$ berarti tidak ada hubungan korelasi. Kemudian dilihat angka koefisien korelasinya untuk melihat tingkat korelasi antara variabel. Untuk hasil hari Sabtu, berdasarkan nilai sig lebih kecil dari nilai signifikasi $(0,002<0,05)$ dengan pengertian ada korelasi. Kemudian dengan nilai koefisien korelasi sebesar 0,703 maka termasuk dalam kategori korelasi tinggi $(0,61-0,8)$. Sehingga dapat disimpulkan bahwa ada korelasi yang tinggi antara nilai $\mathrm{CO}$ dengan jumlah kendaraan. Berdasarkan data pada Tabel 1, dapat digambarkan korelasi antara nilai karbon monoksida dengan jumlah kendaraan berdasarkan titiknya sebagai berikut. 


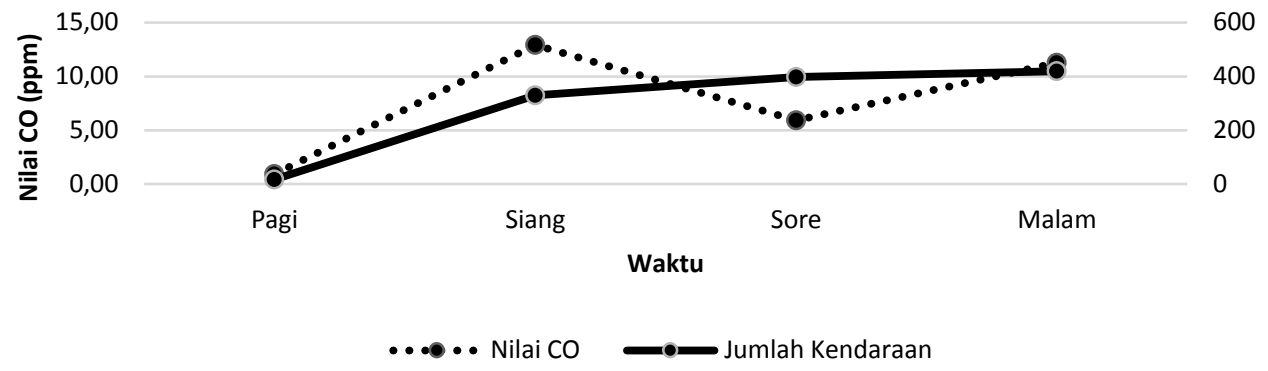

Gambar 1. Perbandingan Nilai CO dengan Jumlah Kendaraan di Titik 1 pada Hari Libur

Di Titik 1 nilai CO dan jumlah kendaraan digambarkan pada Gambar 1, yang mana pada kondisi dari pagi ke siang mengalami peningkatan baik untuk nilai CO maupun jumlah kendaraan, begitu pula pada kondisi sore ke malam. Namun untuk kondisi siang ke sore mengalami hasil yang berbeda meskipun temperatur masih berkisar $33-34^{\circ} \mathrm{C}$. Konsentrasi CO turun dari 12,92 ppm pada siang hari menjadi 5,92 ppm pada sore hari, sedangkan jumlah kendaraan bertambah, yaitu pada siang hari sebanyak 329 unit dan pada sore hari sebanyak 397 unit. Ketidak-selarasan tersebut disebabkan oleh perbedaan aktivitas kendaraan yang melewati titik pengukuran pada waktu yang berbeda. Pada kondisi siang terjadi antrean kendaraan yang masuk ke parkir dalam gedung sehingga terjadi kondisi idle, sedangkan pada sore hari tidak terjadi antrean di mana kendaraan hanya melewati titik pengukuran.

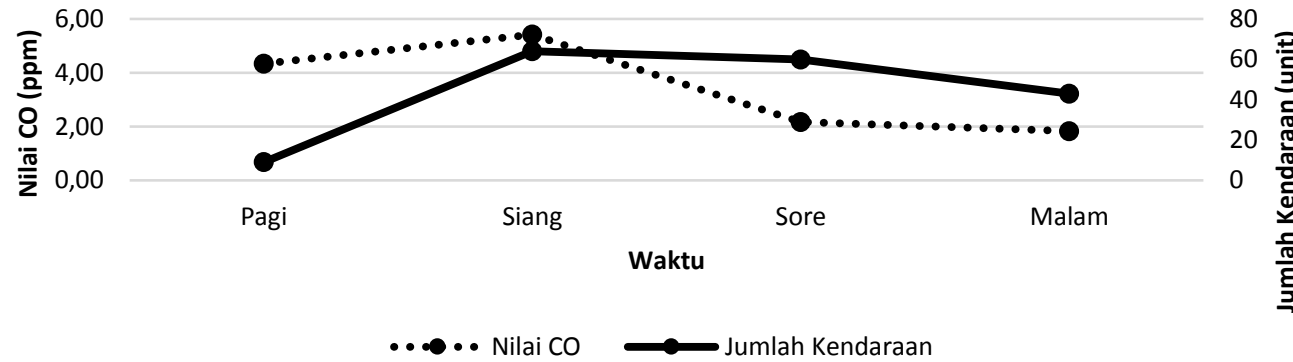

Gambar 2. Perbandingan Nilai CO dengan Jumlah Kendaraan di Titik 2 pada Hari Libur

Selanjutnya di Titik 2 yang digambarkan pada Gambar 2, kenaikan dan penurunan jumlah kendaraan di Titik 2 diikuti dengan kenaikan dan penurunan nilai CO pula. Pada kondisi siang hari, terjadi idle pada Titik 2 mengingat letak Titik 2 yaitu di dekat pintu masuk ke dalam mall di mana biasanya menjadi tempat menurunkan pengunjung sehingga terjadi kondisi idle yang dapat memicu kenaikan nilai CO.

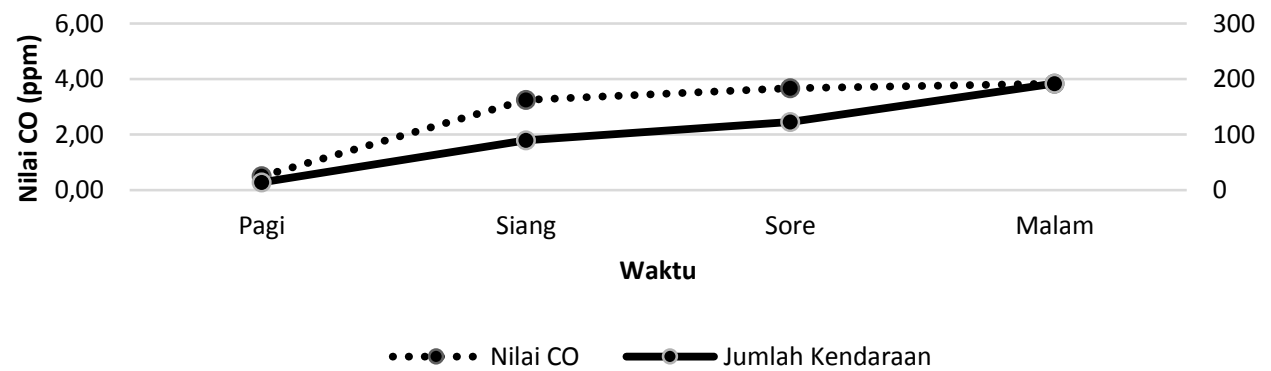

Gambar 3. Perbandingan Nilai CO dengan Jumlah Kendaraan di Titik 3 pada Hari Libur

Merujuk pada Gambar 3 nilai CO dan jumlah kendaraan di Titik 3 berbanding lurus. Titik 3 yang berada di ramp lantai teratas (atap) menyebabkan kendaraan akan mengalami 
perlambatan ketika berbelok menuju area parkir sehingga nilai CO yang terukur lebih tinggi dari Titik 4.
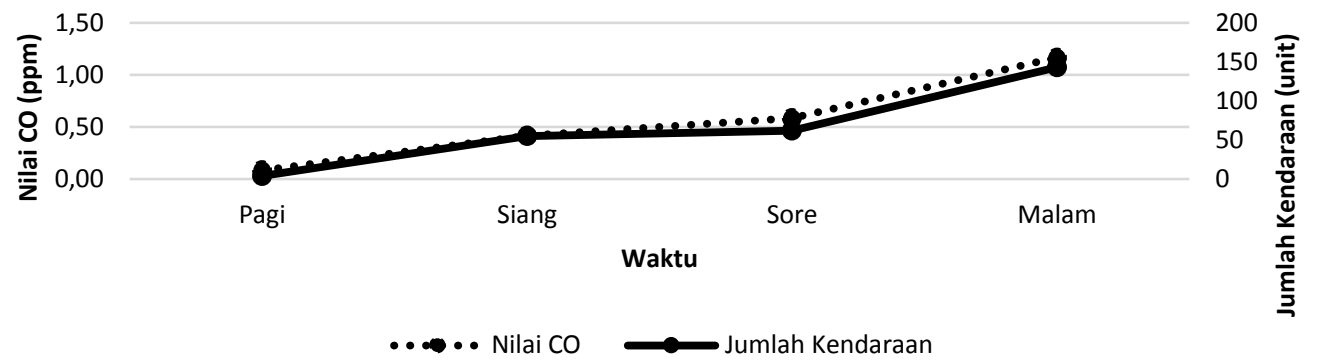

Gambar 4. Perbandingan Nilai CO dengan Jumlah Kendaraan di Titik 4 pada Hari Libur

Perbandingan nilai $\mathrm{CO}$ dan jumlah kendaraan yang berbanding lurus di Titik 4 digambarkan pada Gambar 4 . Titik 4 berada di depan pintu masuk mall yang langsung menuju bioskop, yang biasanya dimanfaatkan untuk menjemput dan menurunkan pengunjung sehingga terjadi kondisi idle di titik ini. Berdasarkan observasi, hanya pada malam hari terjadi idle, sedangkan pada waktu sebelumnya didominasi oleh kendaraan yang hanya melewati titik.

Berikutnya, hasil uji korelasi yang dilakukan pada hari kerja memiliki nilai sig lebih kecil dari nilai signifikasi $(0,000<0,05)$ dengan pengertian ada korelasi. Kemudian dengan nilai koefisien korelasi sebesar 0,798 maka termasuk dalam kategori korelasi tinggi $(0,61$ $0,8)$. Sehingga dapat disimpulkan bahwa ada korelasi yang tinggi antara nilai CO dengan jumlah kendaraan. Berdasarkan data pada Tabel 2, dapat digambarkan korelasi antara nilai karbon monoksida dengan jumlah kendaraan berdasarkan titiknya sebagai berikut.

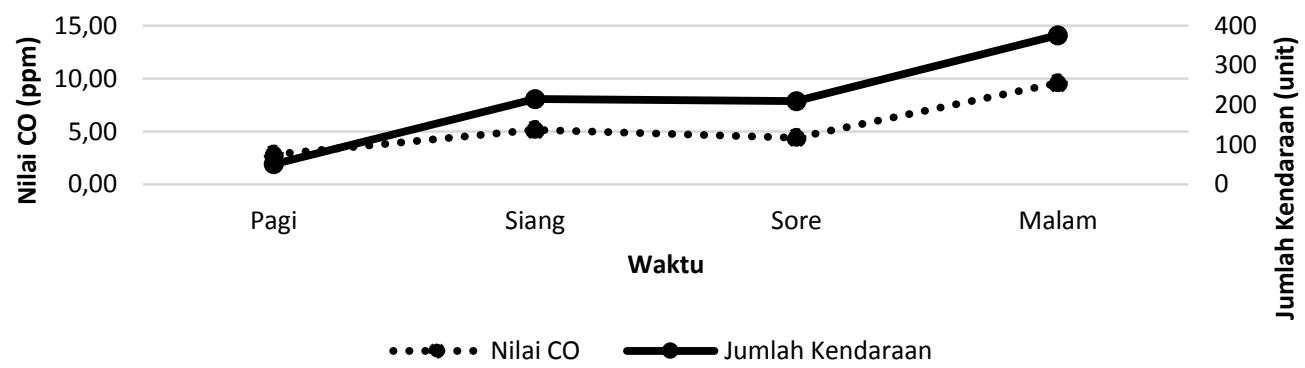

Gambar 5. Perbandingan Nilai CO dengan Jumlah Kendaraan di Titik 1 pada Hari Kerja

Di Titik 1, nilai CO dan jumlah kendaraan berbanding lurus sebagaimana terlihat pada Gambar 5. Tidak ada peningkatan maupun penurunan yang drastis pada titik ini. Berdasarkan pengamatan, tidak banyak pengunjung yang beraktivitas di hari Senin, sehingga tidak terjadi antrean di titik ini.

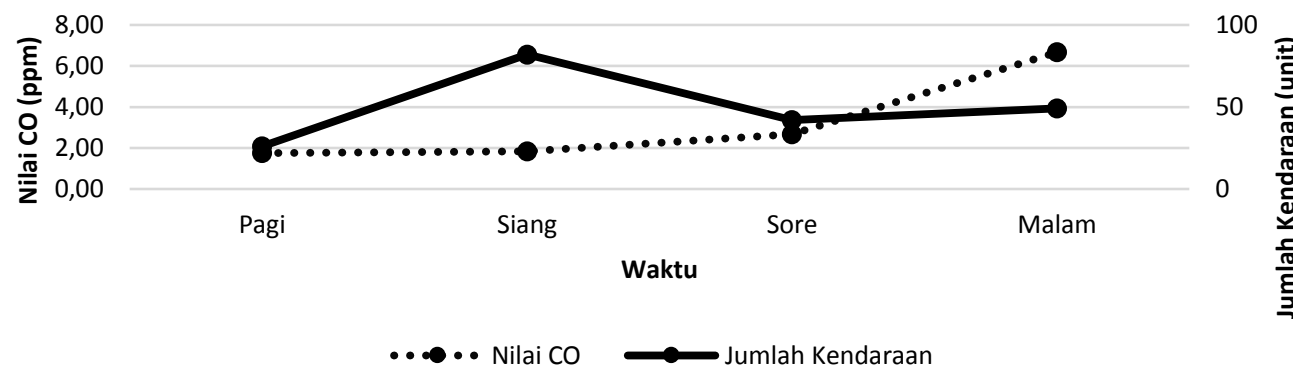

Gambar 6. Perbandingan Nilai CO dengan Jumlah Kendaraan di Titik 2 pada Hari Kerja 
Selanjutnya, berdasarkan Gambar 4.6 pada Titik 2 terjadi kenaikan jumlah kendaraan yang diiringi kenaikan nilai $\mathrm{CO}$, kecuali di kondisi sore. Hal ini disebabakan pada saat siang hari kendaraan cenderung hanya melewati titik pengukuran, sedangkan pada sore terjadi idle yang cukup lama oleh kendaraan jenis lama dan kendaraan yang melintas berkurang. Pada kondisi tersebut, CO meter menunjukkan angka yang cukup tinggi (mencapai >100 ppm). Selain kondisi kendaraan yang idle, perbedaan jenis kendaraan dapat memengaruhi nilai karbon monoksida terukur. Berdasarkan pengamatan nilai karbon monoksida cenderung naik ketika kendaraan tahun keluaran lama berada di daerah pengukuran. Kendaraan tersebut secara fisik mengeluarkan gas buang yang lebih berwarna keabuan yang menunjukkan terjadi pembakaran tidak sempurna sehingga dihasilkan karbon monoksida. Namun tidak menutup kemungkinan adanya faktor luar yang tidak diperhitungkan secara spesifik seperti umur kendaraan, bahan bakar kendaraan, kapasitas mesin, dan periode servis kendaraan memengaruhi kadar emisi yang dikeluarkan kendaraan tersebut (Rorah, 2014).
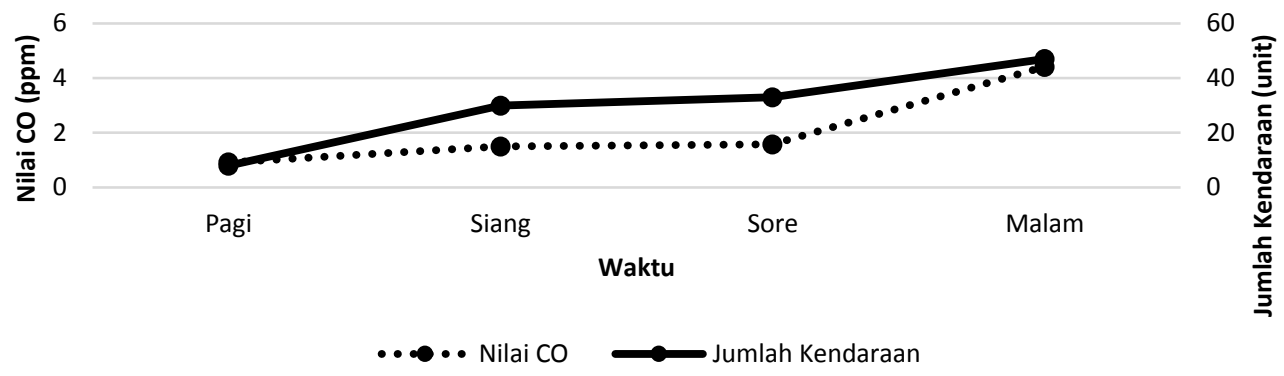

Gambar 7. Perbandingan Nilai CO dengan Jumlah Kendaraan di Titik 3 pada Hari Kerja
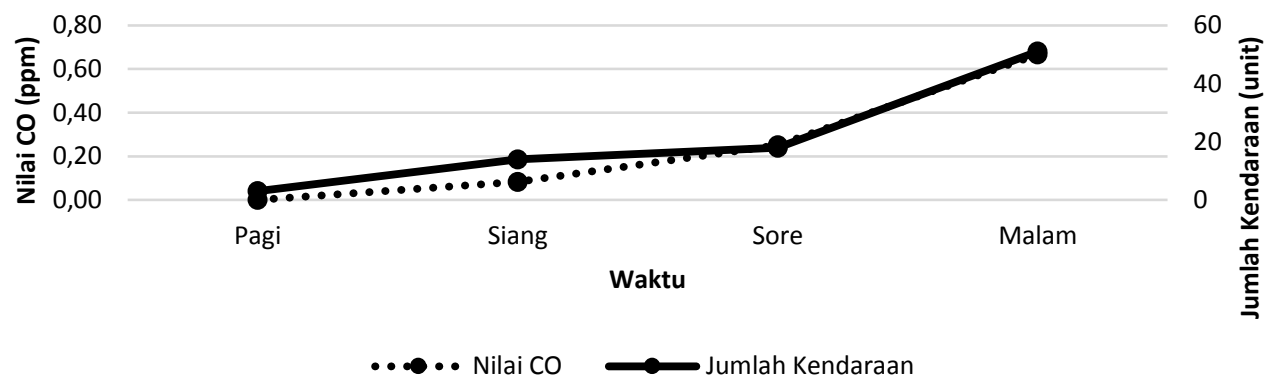

Gambar 8. Perbandingan Nilai CO dengan Jumlah Kendaraan di Titik 4 pada Hari Kerja

Selanjutnya pada Titik 3 dan Titik 4 nilai $\mathrm{CO}$ dan jumlah kendaraan berbanding lurus, yang digambarkan pada Gambar 7 dan Gambar 8. Dapat disimpulkan, dari hasil pengujian statistik pada kedua hari tersebut sama dengan hasil analisis deskriptif yang dipaparkan, yaitu jumlah kendaraan memengaruhi nilai karbon monoksida. Ketidak-linieran yang terjadi seperti pada Titik 1 hari Sabtu disebabkan oleh lebih banyak kendaraan pada sore hari namun hanya melewati titik dan tidak ada idle sehingga karbon monoksida tidak tertumpuk. Sedangkan untuk Titik 2 hari Senin yang juga tidak linier disebabkan oleh adanya kendaraan tahun keluaran lama yang idle di titik tersebut.

\section{KOMPARASI NILAI KARBON MONOKSIDA DI TIAP TITIK}

Perbedaan lokasi, yaitu Titik 1 dan Titik 2 di lantai dasar yang tertutup dan Titik 3 dan Titik 4 terletak di lantai atap yang merupakan area terbuka, dapat memberikan nilai yang berbeda. Perbedaan nilai tersebut dapat dinilai secara statistik dengan menggunakan uji komparasi. Uji Kruskall Wallis memiliki ketentuan yang berdasarkan hipotesis, yaitu: HO : mean nilai karbon monoksida di tiap titik sama 
Ha : tidak seluruh mean nilai karbon monoksida di tiap titik sama

Untuk penarikan simpulan berdasarkan angka chi square hitung lebih besar dari chi square tabel, yaitu pada hari libur sebesar 8,096 dan pada hari kerja sebesar 11,405 menunjukkan angka yang lebih besar dari 7,815, maka Ho ditolak. Serta dengan nilai asymp sig lebih kecil dari nilai signifikasi, yaitu pada hari libur sebesar 0,044 dan pada hari kerja sebesar 0,01 menunjukkan angka yang lebih kecil dari 0,05, maka Ho ditolak. Ho ditolak berarti Ha diterima, yaitu dengan makna ada beda nilai karbon monoksida di tiap titik. Bila melihat angkanya dapat merujuk kembali ke Tabel 1 dan Tabel $\mathbf{2}$ di mana nilai karbon monoksida di tempat tertutup (Titik 1 dan Titik 2) lebih besar daripada di tempat terbuka (Titik 3 dan Titik 4).

Ruang parkir di lantai dasar merupakan pintu masuk utama parkir dalam gedung sehingga kendaraan yang melintas di daerah tersebut lebih banyak, namun memiliki bukaan udara yang sedikit. Keterbatasan ruangan menyebabkan gerakan udara terbatas meskipun telah terjadi turbulensi dari kendaraan yang bergerak dan aliran udara (Fardiaz, 1992). Hal ini menyebabkan lambatnya karbon monoksida terdispersi ataupun berikatan dengan hidroksil sehingga konsentrasi $\mathrm{CO}$ di ruang parkir lantai dasar dapat bernilai tinggi.

Sedangkan pada lantai atap, jumlah kendaraan yang melintas tidak sebanyak di lantai dasar sehingga sumber emisi sedikit. Karbon monoksida juga dapat lebih bebas menyebar mengikuti angin ataupun berikatan dengan ion hidroksil di udara, sehingga nilai CO yang terukur lebih rendah. Menurut Manahan (2005) dalam Azwarani (2012) saat sebuah kendaraan menyala dan menghasilkan $\mathrm{CO}, \mathrm{CO}$ dapat hilang dengan reaksi dengan ion hidroksil di udara ambien. Reaksi antara karbon monoksida (CO) dengan ion hidroksil $\left(\mathrm{HO}^{*}\right)$ menghasilkan karbon dioksida $\left(\mathrm{CO}_{2}\right)$ dan atom hidrogen $\left(\mathrm{H}^{*}\right)$ (Achmad, 2004).

\section{REKOMENDASI PENGELOLAAN KUALITAS UDARA DI RUANG PARKIR AYANI MEGA MALL}

Pengelolaan kualitas udara merupakan upaya yang direkomendasikan agar keadaan udara tidak melebih nilai ambang batas maupun tetap berada di bawah nilai ambang batas agar efek dari pajanan karbon monoksida pada manusia dapat diminimalisir. Rekomendasi pengelolaan kualitas udara di ruang parkir Ayani Mega Mall adalah dengan melakukan peremajaan exhaust fan di mana alat dibersihkan pada periode waktu tertentu agar tidak mengganggu kinerja dalam menghisap udara dalam ruangan. Serta dengan dilakukan pula pemakaian APD (Alat Pelindung Diri) untuk pekerja yang beraktivitas di ruang parkir, khususnya untuk melindungi pernapasan misalnya dengan menggunakan masker. Pemakaian APD di dekat rampa dianjurkan agar petugas parkir yang mengatur kendaraan tidak terpajan emisi yang keluar ketika kendaraan masuk, keluar, ataupun idling.

\section{KESIMPULAN}

Adapun simpulan yang dapat dipaparkan antara lain:

1. Konsentrasi $\mathrm{CO}$ mengalami nilai tertinggi di Titik 1 pada kondisi siang hari untuk hari libur, yaitu dengan angka 12,92 ppm, sedangkan untuk hari kerja nilai tertinggi di Titik 1 pada kondisi malam hari, yaitu dengan angka 9,58 ppm. Nilai tersebut masih di bawah nilai ambang batas ( $25 \mathrm{ppm}$ ) berdasarkan Peraturan Menteri Tenaga Kerja dan Transmigrasi nomor 13 tahun 2011.

2. Konsentrasi CO pada gedung parkir Ayani Mega Mall Pontianak pada kondisi pagi hari dominan tinggi di Titik 2 untuk hari libur dan di Titik 1 di hari kerja. Sedangkan untuk kondisi siang, sore, dan malam hari nilai CO dominan tinggi di Titik 1 baik hari kerja maupun hari libur. Titik 1 dominan tinggi karena letaknya di dekat pintu masuk gedung parkir dan rampa sehingga lebih rentan terkena sumber pencemar. 
3. Hubungan antara jumlah kendaraan terhadap konsentrasi CO memiliki angka koefisien korelasi sebesar 0,703 untuk hari libur dan 0,798 untuk hari kerja, yang berarti memiliki hubungan yang berkorelasi kuat yaitu semakin banyak kendaraan maka nilai $\mathrm{CO}$ juga meningkat.

4. Hubungan komparasi dari uji Kruskall Wallis menghasilkan angka asymp sig sebesar 0,044 untuk hari libur dan sebesar 0,01 untuk hari kerja, yang mana kurang dari taraf signifikansi sebesar 0,05 dengan simpulan ada beda nilai karbon monoksida di tiap titik, yaitu nilai konsentrasi karbon monoksida di tempat tertutup lebih besar daripada di tempat terbuka. Hal ini terjadi karena keterbatasan ruang di tempat tertutup sehingga gerakan udara terbatas, sedangkan di tempat terbuka karbon monoksida dapat langsung menyebar sehingga konsentrasi karbon monoksida kecil.

\section{UCAPAN TERIMA KASIH}

Terima kasih kepada Tim Dosen Skripsi saya (Ibu Yulisa Fitrianingsih, Ibu Suci Pramadita, Ibu Dian Rahayu Jati, dan Pak Kiki P. Utomo), Manajemen Ayani Mega Mall, dosen dan staf Program Studi Teknik Lingkungan, staf Fakultas Teknik Universitas Tanjungpura, serta rekan-rekan yang membantu dalam pengerjaan penelitian ini.

\section{DAFTAR PUSTAKA}

Achmad, R. 2004. Kimia Lingkungan. Yogyakarta: Andi.

Ariliyanti, F. 2012. Pengaruh Kelembaban, Suhu, Arah, dan Kecepatan Angin terhadap Konsentrasi Karbon Monoksida (CO) dengan Membandingkan Dua Volume Sumber Pencemar di Area Pabrik dan di Persimpangan Jalan (Studi Kasus PT. Inti General Yaja Steel dan Persimpangan Jrakah). Semarang: UNDIP.

Azwarani, A. 2012. Studi Perbandingan Kualitas Udara Tempat Parkir Tertutup, Gedung Parkir, dan Tempat Parkir Terbuka Ditinjau dari Parameter Karbon Monoksida (CO) (Studi Kasus: Mal Kelapa Gading). Depok: Universitas Indonesia.

Peraturan Menteri Lingkungan Hidup Nomor 12. 2010. Pelaksanaan Pengendalian Pencemaran Udara di Daerah.

Peraturan Menteri Tenaga Kerja dan Transmigrasi RI. 2011. Nilai Ambang Batas Faktor Fisika dan Faktor Kimia di Tempat Kerja.

Tsuchiya, A. 2006. Carbon Monoxide Measuring in The University Garages. Berkeley, USA: University of California.

Rao, M., dan Rao, H. 1989. Air Pollution. New Delhi: Tata McGraw-Hill Publishing Company Limited.

Rorah, V. 2014. Analisis Kualitas CO dalam Ruang pada Perparkiran Basement dan Upper Ground (Studi Kasus: Mall $X$, Semarang). Semarang: Universitas Diponegoro.

Yarianto. 1999. Analisis Karakteristik Atmosfir di Ujung Lemahabang, Jepara. Tangerang: P2EN-Batan.

Yaziz, M. \& Yen, A. 1986. A Study of the Air Quality in Underground Car Parks with Emphasis on Carbon Monoxide and Airborne Lead. Selangor: Universiti Pertanian Malaysia. 